\title{
ON A REVERSE OF THE TAN-XIE INEQUALITY FOR SECTOR MATRICES AND ITS APPLICATIONS
}

\section{LEILA NASIRI* AND SHIGERU FURUICHI}

Abstract. In this short paper, we establish a reverse of the derived inequalities for sector matrices by Tan and Xie, with Kantorovich constant. Then, as application of our main theorem, some inequalities for determinant and unitarily invariant norm are presented.

Mathematics subject classification (2020): Primary 47A63; Secondary 46L05, 47A60, 26 D15.

Keywords and phrases: Sector and accretive matrices, the Kantorovich constant, numerical range, determinant and norm inequality.

\section{REFERENCES}

[1] M. Alakhrass, A note on sectorial matrices, Linear Multilinear Algebra 68 (11)(2020), 2228-2238.

[2] R. Bhatia, Matrix Analysis, Springer-Verlag, New York, 1997.

[3] R. Bhatia, Positive definite matrices, Princeton University Press, Princeton, 2007.

[4] R. Bhatia AND F. KitTAneh, Notes on matrix arithmetic-geometric mean inequalities, Linear Algebra Appl. 308 (1-3) (2000), 203-211.

[5] M. BAKHERAD, Refinements of a reversed AM-GM operator inequality, Linear Multilinear Algebra 64 (9) (2016), 1687-1695.

[6] S. DRURY AND M. Lin, Singular value inequalities for matrices with numerical ranges in a sector, Oper. Matrices 8 (2014), 1143-1148.

[7] S. Furuichi AND H. R. Moradi, Advances in mathematical inequalities, De Gruyter, 2020.

[8] T. Furuta, J. Mićić, J. PeČArić And Y. SeO, Mond-Pečarić method in operator inequalities, Element, Zagreb, 2005.

[9] R. A. Horn And C. R. Johnson, Matrix Analysis, Cambridge University Press, 2013.

[10] W. LIOA AND J. WU, Improved operator Kantorovich and Wielandt inequalities for positive linear maps, Filomat 31 (3) (2017), 871-876.

[11] M. LIN, Squaring a reverse AM-GM inequality, Studia Math. 215 (2013), 189-194.

[12] M. LiN, Extension of a result of Hanynsworth and Hartfiel, Arch. Math. 1 (2015), 93-100.

[13] M. Lin, Some inequalities for sector matrices, Oper. Matrices 10 (4) (2016), 915-921.

[14] M. Raissouli, M. S. Moslehian And S. Furuichi, Relative entropy and Tsallis entropy of two accretive operators, C. R. Acad. Sci. Paris Ser. I, 355 (2017), 687-693.

[15] F. TAN AND A. XIE, An extension of the AM-GM-HM inequality, Bull. Iran. Math. Soc. 46 (2020), 245-251.

[16] C. YANG AND F. Lu, Some generalizations of inequalities for sector matrices, J. Inequal. Appl. 2018 (2018), Art. 183.

[17] C. YANG AND F. LU, Some reverse mean inequalities for operators and matrices, J. Inequal. Appl. 2019 (2019), Art. 115.

[18] C. YANG AND F. LU, Inequalities for the Heinz mean of sector matrices involving positive linear maps, Ann. Funct. Anal. 11 (2020), 866-878.

[19] F. ZHANG, A matrix decomposition and its applications, Linear Multilinear Algebra 63 (10) (2015), 2033-2042.

[20] D. Zhang, L. Hou AND L. MA, Properties of matrices with numerical ranges in a sector, Bull. Iran. Math. Soc. 43 (6) (2017), 1699-1707. 